\title{
Development of Silver Nanoparticles/PEG/Glycerine Composite for Antibacterial Effect using Leaf Extract of Ocimum sanctum and Ocimum basilicum
}

\author{
Diksha B. Lade*, Dayanand P. Gogle, Bipin D. Lade \\ Plant Physiology Laboratory, Department of Botany, RTM Nagpur University, Nagpur - 440 001, Maharashtra, India.
}

\section{ART IC LE DETAILS}

\section{Article history:}

Received 20 September 2018

Accepted 16 October 2018

Available online 11 November 2018

\section{Keywords:}

Silver Nanoparticles

Ocimum sanctum

Ocimum basilicum

Biopolymer

\begin{abstract}
A B S T RAC T
The main purpose of the experiment is to use green synthesis method for silver nanoparticles (SNP) fabrication using phytochemical and functional groups inherent in aqueous leaf extract of Ocimum sanctum and Ocimum basilicum for formulation of polyethylene glycol (PEG)/ Glycerine film. The SNP synthesis reaction is performed under sun condition and change in colour from light brown to dark brown was the initial indication, observed for nanoparticles synthesis. The $95 \mathrm{~mL}$ of $0.001 \mathrm{M} \mathrm{AgNO}_{3}$ is mixed with $5 \mathrm{~mL}$ of leaf extract and reaction performed under Sun light at alkaline $\mathrm{pH} 8$ was found efficient to produced stable NP. The synthesized SNP are mixed with $(10 \%, 50 \%, 100 \%, 150 \%, 200 \%$ and 250\%), polyethylene glycol (PEG):glycerine (G) in 1:1 ratio to form a film. The UV-spectroscopic analysis confirms absorption at $420-430 \mathrm{~nm}$ for synthesized SNP. The FTIR characterization determines alkynes (terminal), $1^{\circ}, 2^{\circ}$ amines, amides, nitriles, alkynes, alkyl halides functional group from $O$. sanctum (OS) leaf extract and aldehydes, alkynes (terminal), alkyne, alkene, from 0 . basilicum (OB) leaf extract responsible for reducing and capping silver nitrate to form nanoparticles. The SEM analysis verify that the $O$. sanctum based nanoparticles are spherical in shape although $O$. basilicum based nanoparticles have bright contrast coral reef like morphology. The average zeta potential of silver nanoparticles was found to be $27.74 \mathrm{mV}$ and $23.50 \mathrm{mV}$ that are embedded in Ocimum sanctum-SNP/PEG and Ocimum basilicum-SNP/PEG films. Also, the average diameters of SNP in Ocimum sanctum-SNP/PEG and in Ocimum basilicum-SNP/PEG was found to be $463.2 \mathrm{~nm}$ and $43.0 \mathrm{~nm}$. These Sun light mediated SNP shows antimicrobial activity against $E$. coli and $S$. aureous pathogens.
\end{abstract}

\section{Introduction}

Ocimum is a genus of aromatic annual and perennial herbs, shrubs in the family Lamiaceae, native to the tropical and sub temperate part of globe, with the large number of species found in Africa and few species of Basil are native to India. The word Ocimum is derived from the Greek word "ozo" meaning smell and is called as "king of herbs" due to its immense use in traditional system of medicine, perfumery and pharmaceutical industry [1]. The diversity of Ocimum is geographical distributed in three main regions Tropical and subtropical regions of Africa, Tropical Asia and Tropical parts of America (Brazil) up to an altitude of about $1800 \mathrm{~m}$ from the mean sea level [1]. In India, so far about nine species of Ocimum have been reported including three exotic species namely $O$. americanum L., $O$. minimum L., and $O$. africanum Lour [1]. The Ocimum sanctum also called as Ocimum tenuiflorum (holybasilor tulsi) is native to the Indian subcontinent and cultivated for religious and traditional medicine purposes of its essential oil. Similarly, Ocimum basilicum (sweet basil) is economic plant grown in India, Iran, and in few warm regions of Africa [2].

The chemical composition of Ocimum species shows clear variation with respect to seasons. The major oil constituents from different Ocimum plant species include 1, 8-cineol, linalool, pinene, eugenol, camphor, methyl chavicol, ocimene, terpinene, and limonene [3]. Ocimum species is widely used in medicine for treating digestive disorders, such as stomach ache, diarrhoea, kidney complaints and infections, whooping cough and various types of fever. Moreover, they are use in curing or show antibacterial, ameliorative, antidiabetic, genoprotective, analgesic, antistress, hepatoprotective, memory booster, antipyretic, radioprotective, effect on testicular function, anticancer and anti-cataract effect. It is also effective in Alzheimer's disease, oral submucous fibrosis [4], anti-inflammatory and anti-nociceptive [5, 6].
The medicinal plant extracts are used in nanoscience for developments of formulation for varied application in textile, mobile phones, geo sensing technology, paper, food, fertilizers, pesticides and agrochemical industries. The silver $(\mathrm{Ag})$ is the most compatible with biological system, living organisms and medicine which make ideal candidate to form silver nanoparticles AgNPs $(<100 \mathrm{~nm}$ ) for wound healing, burns and other medical purposes [7]. Recently, the plant mediated silver nanoparticles are complexed with potential, biodegradable polymers to enhance better releasing and effective antimicrobial activity. The one of the important polymer is polyethylene glycol (PEG) which is known as an osmotictype laxative [8] referred as polyethylene oxide (PEO), that could be cross linked into networks, can hold high water content and forms hydrogels. PEG is a condensation polymer of ethylene oxide and water. Polyethylene glycols do not hydrolyze upon storage, inhibit growth of molds and beneficial for biological, chemical and pharmaceutical applications [9].

Therefore, in present study an attempt have been made to formulate silver nanoparticles using plant extract of $O$. sanctum and $O$. basilicum for film/composite development using blend of polyethylene glycols and glycerine as a polymer to give assistance for film formation and to enhance its releasing properties. The characterization and measurements are performed to depict the importance of formulated SNP/PEG/G composite in antibacterial application.

\section{Experimental Methods}

\subsection{General Reagents and Solutions}

The $250 \mathrm{~mL}$ conical flask, $100 \mathrm{~mL}$ measuring cylinder, mortar, pestle, cover slip, various organic solvents and doubled distilled water (Millipore Milli-Q ultrapure water system). The $1 \mathrm{mM}$ sodium hydroxide $(\mathrm{NaOH})$, hydrochloric acid $(\mathrm{HCl})$, silver nitrate $\left(\mathrm{AgNO}_{3}\right)$, glycerine $(\mathrm{G})$ polyethylene glycol (PEG) is purchased from Sigma-Aldrich. The plant samples of $O$. sanctum and $O$. basilicum have been collected from predefined places mentioned in Table 1 and their leaf extract were used for experimentation. 
Table 1 Display the picture, location and possible antibacterial compounds present in Oscimum sanctum and Ocimum basillicum

\begin{tabular}{|c|c|c|c|}
\hline S. No. & Plant species & Location & Possible Antibacterial Compounds \\
\hline 1 & $\begin{array}{l}\text { Oscimum } \\
\text { sanctum }\end{array}$ & $\begin{array}{l}\text { Latitude } \\
\text { N20 } 8^{\prime} 57 \\
\text { Longitude } \\
\text { E 780 } 59^{\prime} 27\end{array}$ & $\begin{array}{l}\text { Monoterpenes, camphor, cineole, } \\
\text { estragol,eugenol, } \alpha \text {-elemene, bornyl } \\
\text { acetate, } \alpha \text {-, } \beta \text {-pinenes, sesquiterpenes, } \\
\text { camphene, methyl eugenol germacrene, } \\
\text { campesterol, caryophyllene, bisabolene, } \\
\text { methyl chavicol and eucalyptol [10]. }\end{array}$ \\
\hline 2 & $\begin{array}{l}\text { Ocimum } \\
\text { basillicum }\end{array}$ & $\begin{array}{l}\text { Latitude } \\
\text { N2 }{ }^{\circ} 8^{\prime} 57 \\
\text { Longitude } \\
\text { E } 78^{0} 59^{\prime} 27\end{array}$ & $\begin{array}{l}\text { Methyl eugenol,methyl chavicol, } \\
\text { terpinolene, eugenol, cubenol, linalool, } \\
\text { methyl cinnamate-rich [11], alkaloids, } \\
\text { tannins, flavonoids, cholesterol, } \\
\text { terpernoids, glycosides, phenols, cardiac } \\
\text { glycosides, carbohydrates, and } \\
\text { phlobatannins [12]. }\end{array}$ \\
\hline
\end{tabular}

\subsection{Instruments and Bacterial Strains}

The UV spectrophotometry (Shimadzu Dual Beam spectrometer, ModelUV-1650 PC), Zeiss light microscope of Stemi DV4 (made in Germany), Fourier-transform infrared spectroscopy (FTIR), scanning electron microscopic (SEM), water bath, microwave oven and weighing balance were used in this experiment. Bacterial strains used in present antimicrobial study are Escherichia coli (ATCC no.11105) and Staphylococcus aureus (ATCC no. 6538).

\subsection{Leaf Extracts Preparation}

The $10 \mathrm{~g}$ leaf of 0 . sanctum and 0 . basilicum washed with tap water, dried at room temperature and macerated using mortar and pestlein 75 $\mathrm{mL}$ autoclaved double distilled water for five min. The extract was filtered using double coated cotton muslin cloth and the filtrate was set for centrifugation at $4000 \mathrm{rpm}$ or 1792 relative centrifugal force (RCF) or G force for $10 \mathrm{~min}$. The $65 \mathrm{~mL}$ of supernatant was stored in refrigerator for further fabrication of SNP.

\subsection{Silver Nanoparticle Synthesis}

The $95 \mathrm{~mL}$ of $0.001 \mathrm{M}$ silver nitrate $\left(\mathrm{AgNO}_{3}\right)$ is mixed with the $5 \mathrm{~mL}$ leaf extract of 0 . sanctum and 0 . basilicum independently. The reaction was performed in Sun light (June 2018; temperature $35-45^{\circ} \mathrm{C}$ ) and after $5 \mathrm{~min}$ $0.0001 \mathrm{M}, \mathrm{NaOH}$ solution was added to mixture solution to maintain alkaline pH 8 (Fig. 1). The reaction mixture of silver nitrate and leaf extract was observed through visual change in colour [7].



Fig. 1 A diagrammatic representation of silver nanoparticles synthesis, using leaf extract of $O$. sanctum under specific conditions

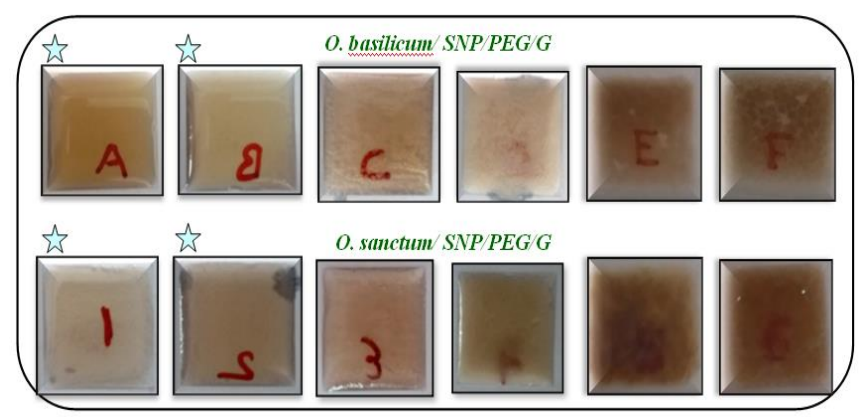

Figure 2. Shows the synthesized films of 0 . basilicum/ $S N P / P E G / G$, A: $(100 \% \mathrm{PEG}+100 \% \mathrm{G}), \quad$ B: $(150 \% \mathrm{PEG}+150 \% \mathrm{G}), \quad$ C: $\quad(200 \% \mathrm{PEG}+200 \% \mathrm{G}), \quad$ D: $(250 \% \mathrm{PEG}+250 \% \mathrm{G}), \quad$ E: $\quad(10 \% \mathrm{PEG}+10 \% \mathrm{G}), \quad$ F: $\quad(50 \% \mathrm{PEG}+50 \% \mathrm{G})$, and $O$. sanctum $/ S N P / P E G / G, \quad \mathbf{1}:(100 \% \mathrm{PEG}+100 \% \mathrm{G}), \quad 2: \quad(150 \% \mathrm{PEG}+150 \% \mathrm{G}), \quad 3:$ $(200 \% \mathrm{PEG}+200 \% \mathrm{G}), \quad$ 4: $(250 \% \mathrm{PEG}+250 \% \mathrm{G}), \mathbf{5 :}(10 \% \mathrm{PEG}+10 \% \mathrm{G})$ and $\mathbf{6 :}$ $(50 \% \mathrm{PEG}+50 \% \mathrm{G})$. Note: indicates best film in term of formation, texture, quality, transparency and dries at RT

https://doi.org/10.30799/jnst.161.18040517

\subsection{Preparation of SNP/PEG/G Biopolymer}

The polyethylene glycol 10\%, 50\%, 100\%, 150\%, 200\% and 250\% mixed with $1 \mathrm{~mL}$ of synthesized SNP solution and glycerine was added (1:1) ratio with respect to PEG. The SNP/PEG/G biopolymer complexes solution was then kept in water bath at $70{ }^{\circ} \mathrm{C}$ for $30 \mathrm{~min}$. Finally, the SNP/PEG/G biopolymer was set for microwave oven heat burst of $30 \mathrm{sec}$ for five times. The pale yellow colour and homogenous solution of SNP/PEG/G biopolymer complexes are allowed to cool down and poured over cover slip (22 mm size) (Fig. 2).

\subsection{Characterization of Silver Nanoparticles}

The 0 . sanctum (OS) and $O$. basilicum (OB) leaf extract, Ocimum sanctum-nanoparticles (OS-SNP) and Ocimum basilicum-nanoparticles (OB-SNP) and film (OS-SNP/PEG/G), (OB-SNP/PEG/G) fetched for characterization, measurements and application activities.

\subsection{UV-Visible Spectroscopy}

The instrument was set for base line correction and auto zero using $\mathrm{ddH}_{2} \mathrm{O}$ and $1 \mu \mathrm{L}$ of extracts, SNP, films OS-SNP/PEG/G and OB-SNP/PEG/G were placed on the central top of the cuvette of nanophotometer for measuring UV-Vis spectra at a resolution of 200-800 $\mathrm{nm}$.

\subsection{FTIR Spectroscopy}

The $O$. sanctum and $O$. basilicum leaf extract and their silver nanoparticles (OS-SNP) and (OB-SNP) were characterised using FTIR in 4000 to $450 \mathrm{~cm}^{-1}$ at a resolution of $4 \mathrm{~cm}^{-1}$.

\subsection{Solubility Test}

The solubility test of the prepared films (OS-SNP/PEG/G, OBSNP/PEG/G) has done by adding distilled water over film in petri dishes. The time to dissolve film, photographs and videos have recorded during the test. Furthermore, the individual solubility of PEG at RT and boiling at $70{ }^{\circ} \mathrm{C}$ for $20 \mathrm{~min}$ and glycerine at RT was done in various solvents to check solubility potential.

\subsection{SEM Analysis}

The OS-SNP, OB-SNP, OS-SNP/PEG and OB-SNP/PEG films without glycerine were used for scanning electron microscopic analysis using Carl Zeiss SEM-EVO18 with accelerated voltage of $130 \mathrm{KV}$. The morphology and size of silver nanoparticles and SNP/PEG-films were investigated using SEM specific software. The magnification was set at $4.85 \mathrm{KX}$ for (OS), 9.83 $\mathrm{KX}(\mathrm{OB}), 4.00 \mathrm{KX}$ for OS/SNP/PEG/G and 3.39 KX for OB/SNP/PEG/G.

\subsection{DLS Size and Zeta Potential Analysis}

The synthesis OS-SNP/PEG and OB-SNP/PEG films were fetched for determination of size analysis and to identify zeta potential surface charge over nanoparticles in films. The nanoparticles are subjected to Brownian motions due to thermal energy that produces Rayleigh scattering. The size of nanoparticles in film are determined by using Particle Sizing Systems Inc. Santa Barbara, Calif., USA at CICR-CIRCOT Mumbai, India and the Number-Weighted Gaussian distribution analysis (solid particle), Intensity-wt, volume-wt NICOMP distribution and zeta potential in (mV) were calculated.

\subsection{Antimicrobial Test}

Antimicrobial properties of $O$. sanctum and 0 . basilicum leaf extract, OSSNP and OB-SNP, OS-SNP/PEG/G and OB-SNP/PEG/G film against Escherichia coli and Staphylococcus aureus is done as per the protocol followed by [10]. The extract, SNP and their films are placed on culture of $E$. coli and $S$. aureus spreaded agar plates. The inhibition of bacteria has visualized after $24 \mathrm{~h}$ of incubation at $37{ }^{\circ} \mathrm{C}$ and the zone of inhibition was measured.

\section{Results and Discussion}

\subsection{Visual Conformation}

The change in colour from light brown to dark brown colour was visualised by naked eyes and addition of $1 \mathrm{mM} \mathrm{NaOH}$ to the reaction mixture to maintain pH 8 make the solutions' colour more dark (Fig. 1).

\subsection{UV-Visible Analysis}

The UV-visible analysis has been done for leaf extract of $O$. sanctum and o. basilicum, their silver nanoparticles (OS-SNP and OB-SNP) and films OS- 
SNP/PEG/G and OB-SNP/PEG/G (Fig. 3). The synthesized SNP exhibited a well-defined absorption peak at $430 \mathrm{~nm}$ for $O$. basilicum and $420 \mathrm{~nm}$ for $O$. sanctum.

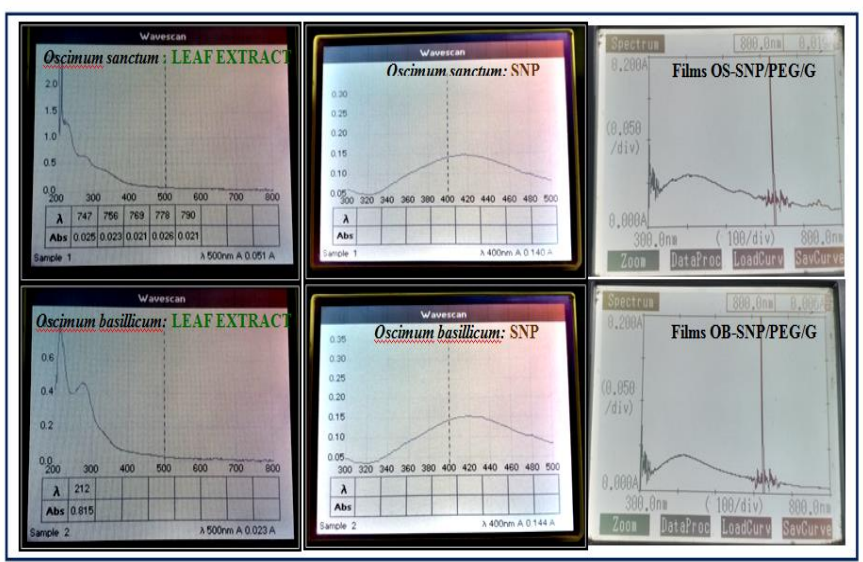

Fig.3 UV spectrophotometer analysis of leaf extract of Oscimum sanctum, Oscimum basillicum, SNP and films OS-SNP/PEG/G, OB-SNP/PEG/G formed by utilizing the leaf extract of $O$. sanctum and $O$. basillicum as capping agent

\subsection{Nanoparticles Concentration}

The concentration parameters in nanophotometer was set as wavelength $420 \mathrm{~nm}$, units picomole $/ \mu \mathrm{L}$, pathlength $10 \mathrm{~mm}$ and factor 50.0 . The concentration parameters of $O$. sanctum-NP at wavelength $410 \mathrm{~nm}$ were found to be 7.0 picomole $/ \mu \mathrm{L}$ and absorbance $0.140 \AA$. Likewise, the concentration parameter of $O$. basillicum-NP at wavelength $420 \mathrm{~nm}$ was found to be 7.500 picomole $/ \mu \mathrm{L}$ with absorbance $0.150 \AA$.

\subsection{FTIR Analysis}

The FTIR was used to identify the potential functional group, chemical compounds and biomolecules present in the leaf extract of $O$. sanctum and 0 . basilicum that are involved in capping and reducing $\mathrm{Ag}^{+}$ions to $\mathrm{Ag}^{0}$. The Fig. 4 and Table 2 shows the FTIR spectra of leaf extract of 0 . sanctum and O. basilicum and their SNPs.
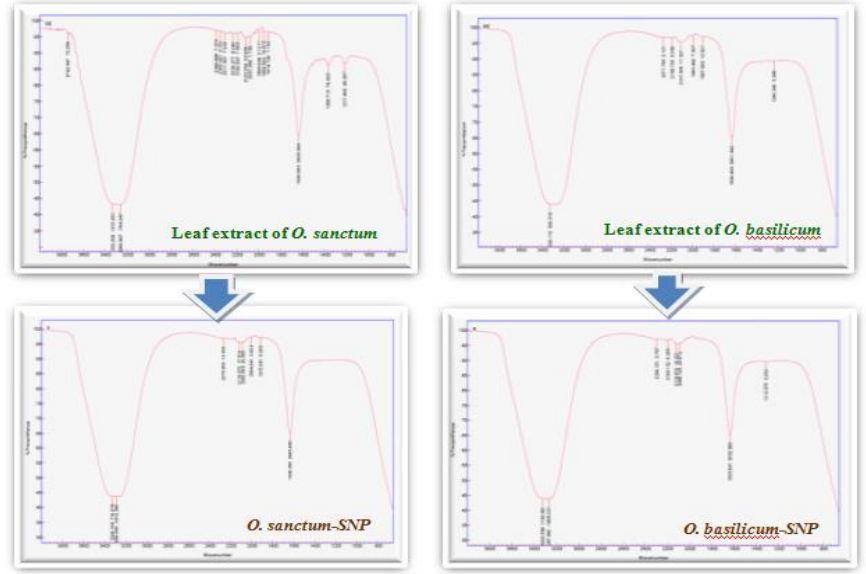

Fig. 4 FTIR spectrum of $O$. sanctum, $O$. basillicum leaf extract, $O$. basillicum-SNP and O. sanctum-SNP

Table 2 Functional group detected on the basis of FTIR spectra for O. sanctum (OS) and O. basilicum (OB) leaf extract, OS-SNP and OB-SNP with its absorption range, absorption frequency strength and characteristic bond

\begin{tabular}{|c|c|c|c|c|c|c|c|}
\hline Peaks & Absorption & Characteristic bond & Functional group & Peaks & Absorption & Characteristic bond & Functional group \\
\hline \multicolumn{4}{|c|}{ Ocimum sanctum (OS) leaf extract } & \multicolumn{4}{|c|}{ Ocimum sanctum-Nanoparticles (OS-SNP) } \\
\hline 1 & 3333.2041310 .461 & $-\mathrm{C} \equiv \mathrm{C}-\mathrm{H}: \mathrm{C}-\mathrm{H}$ stretch & alkynes (terminal) & 1 & 3328.169716 .474 & $-\mathrm{C} \equiv \mathrm{C}-\mathrm{H}: \mathrm{C}-\mathrm{H}$ stretch & alkynes (terminal) \\
\hline 2 & $3260.907-784.047$ & $\mathrm{~N}-\mathrm{H}$ stretch & $\begin{array}{l}1^{\circ}, 2^{\circ} \text { amines, } \\
\text { amides }\end{array}$ & 2 & $3289.560-3012.368$ & $-\mathrm{C} \equiv \mathrm{C}-\mathrm{H}: \mathrm{C}-\mathrm{H}$ stretch & alkynes (terminal) \\
\hline 3 & 2236.2778 .240 & $\mathrm{C} \equiv \mathrm{N}$ stretch & Nitriles & 3 & 2270.80312 .333 & $\mathrm{H}-\mathrm{C}=\mathrm{O}: \mathrm{C}-\mathrm{H}$ stretch & aldehydes \\
\hline 4 & 2193.5677 .590 & $-\mathrm{C} \equiv \mathrm{C}-$ stretch & Alkynes & 4 & 2118.07517 .519 & $-\mathrm{C} \equiv \mathrm{C}-$ stretch & alkynes \\
\hline 5 & 2120.25432 .908 & $-\mathrm{C} \equiv \mathrm{C}-$ stretch & Alkynes & 5 & 1636.3502845 .490 & $-\mathrm{C}=\mathrm{C}-$ stretch & alkenes \\
\hline 6 & 1638.6832903 .064 & $\mathrm{~N}-\mathrm{H}$ bend & $1^{\circ}$ amines & - & 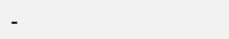 & - & - \\
\hline 7 & 1369.71574 .300 & $\mathrm{C}-\mathrm{H}$ rock & Alkanes & - & - & - & - \\
\hline 8 & 1217.44595 .397 & $\mathrm{C}-\mathrm{H}$ wag $(-\mathrm{CH} 2 \mathrm{X})$ & alkyl halides & - & - & - & - \\
\hline \multicolumn{4}{|c|}{ Ocimumbasilicum (OB) leaf extract } & \multicolumn{4}{|c|}{ Ocimumbasilicum-Nanoparticles (OB-SNP) } \\
\hline 1 & 3328.169716 .474 & $-\mathrm{C} \equiv \mathrm{C}-\mathrm{H}: \mathrm{C}-\mathrm{H}$ stretch & alkynes (terminal) & 1 & 3323.5861182 .891 & $\begin{array}{l}\text { O-H stretch, } \\
\text { H-bonded }\end{array}$ & alcohols, phenols \\
\hline 2 & $3289.560-3012.368$ & $-\mathrm{C} \equiv \mathrm{C}-\mathrm{H}: \mathrm{C}-\mathrm{H}$ stretch & alkynes (terminal) & 2 & $3267.842-1906.321$ & $\mathrm{~N}-\mathrm{H}$ stretch & $1^{\circ}, 2^{\circ}$ amines, amides \\
\hline 3 & 2270.80312 .333 & $\mathrm{H}-\mathrm{C}=\mathrm{O}: \mathrm{C}-\mathrm{H}$ stretch & aldehydes & 3 & 2119.81016 .221 & $\mathrm{C} \equiv \mathrm{N}$ stretch & nitriles \\
\hline 4 & 2118.07517 .519 & $-\mathrm{C} \equiv \mathrm{C}-$ stretch & Alkynes & 4 & 1635.9913032 .993 & $\mathrm{~N}-\mathrm{H}$ bend & $1^{\circ}$ amines \\
\hline 5 & 1636.3502845 .490 & $-\mathrm{C}=\mathrm{C}-$ stretch & Alkenes & 5 & 1312.0753 .253 & C-O stretch & $\begin{array}{l}\text { alcohols, ethers } \\
\text { carboxylic acids, esters, }\end{array}$ \\
\hline
\end{tabular}

\subsection{Light Microscopic Analysis}

The best formulated films using 0 . sanctum and 0 . basilicum are observed under light microscope in 10X focus for observation of SNP in PEG/G composite (Fig. 5).

\subsection{Solubility Check}

The OS-SNP/PEG/G and OB-SNP/PEG/G films were used to check solubility in double distilled water (Fig. 6). From the tested samples of concentration $10 \%, 50 \%, 100 \%, 150 \%, 200 \%$ and $250 \%$ glycerine and PEG (1:1) ratio, the sample B and 2 (150\%) have optimized for giving best texture, film forming capability and solubility in water. Besides, the solubility of glycerine has performed in different solvents. However, various concentrations of PEG were used to check the solubility potential and dissolve time at room temperature (RT), at $70{ }^{\circ} \mathrm{C}$ (Table 3).

\subsection{Antimicrobial Potential of SNP/PEG/G Film}

Antimicrobial potential of OS-SNP/PEG/G and OB-SNP/PEG/G film in $(150 \% \mathrm{PEG}+150 \% \mathrm{G})$ concentration were tested against Escherichia coli and Staphylococcus aureus lawn (Fig. 7). A small inhibition could be seen in 0 . sanctum/SNP/PEG/G $(150 \% \mathrm{PEG}+150 \% \mathrm{G})$ films however it is not prominent. The other combination of SNP and $(P E G+G)$ shows no inhibition.

https://doi.org/10.30799/jnst.161.18040517

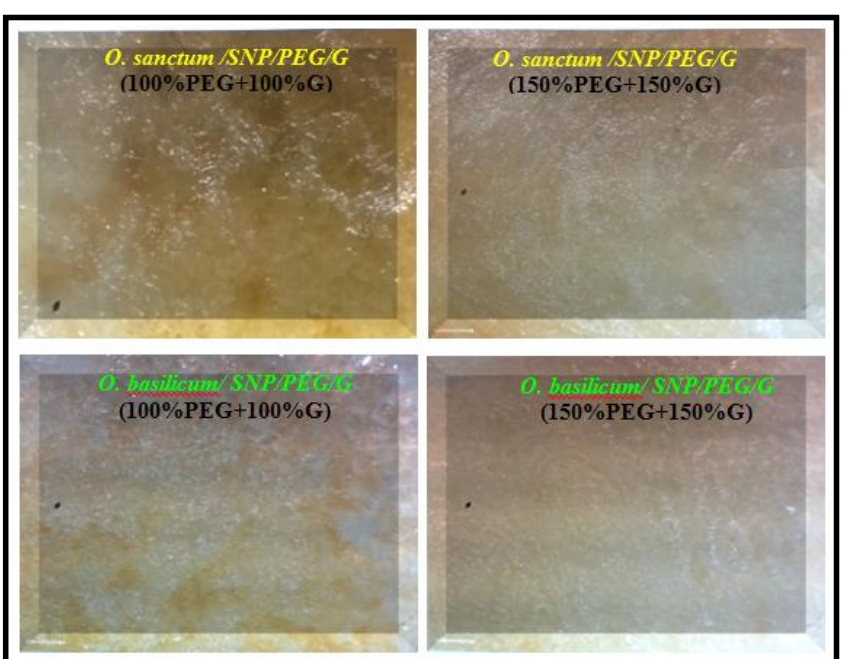

Fig. 5 Represents the light microscopic structure of SNP/films samples of O. basilicum and $O$. sanctum synthesized using different concentration of PEG and glycerine $(100 \%$ PEG+100\%G; $150 \%$ PEG+150\%G) 

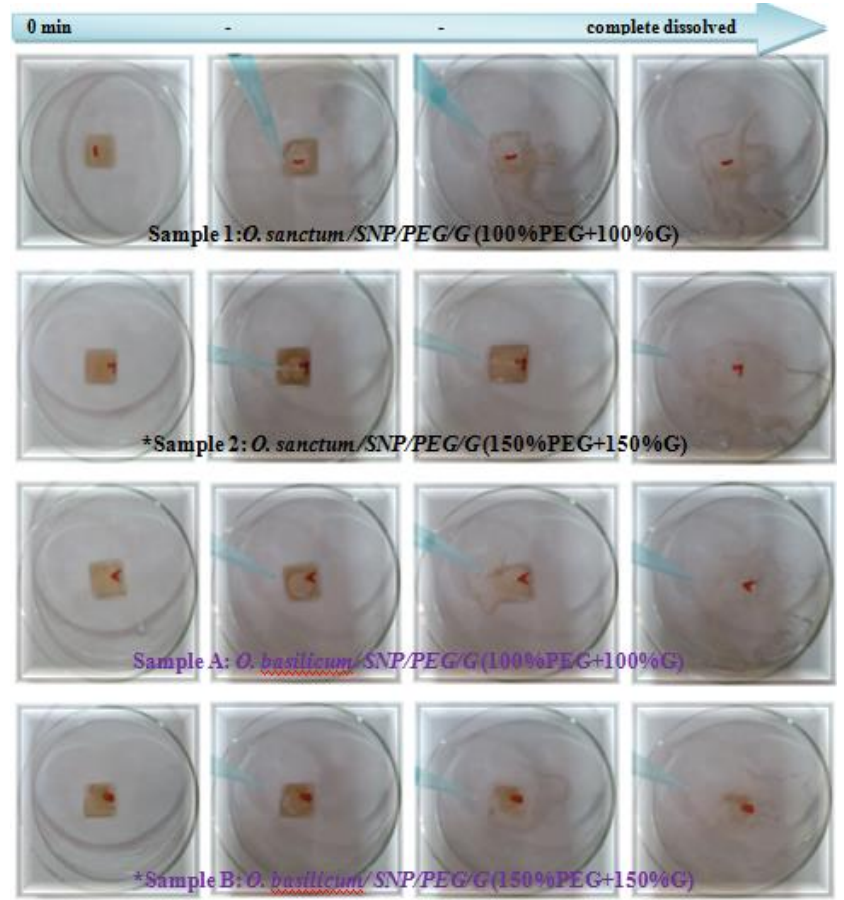

Fig. 6 Solubility behaviour of $O$. basilicum/SNP/PEG/G and 0 . sanctum $/ S N P / P E G / G$ succeeding very few seconds of water exposure
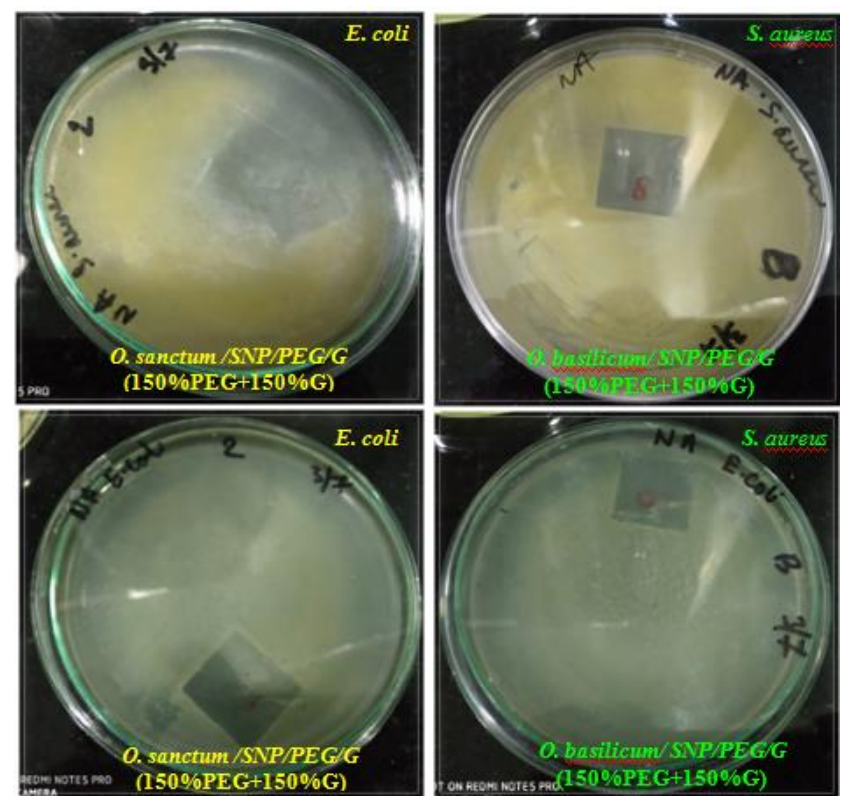

Fig. 7 Antimicrobial potential of OB-SNP/PEG/G and OS-SNP/PEG/G composite formed by $(150 \% \mathrm{PEG}+150 \% \mathrm{G})$ concentration against $E$. coli and $S$. aureus

Table 3 Solubility potential of glycerine and PEG at room temperature (RT)

\begin{tabular}{lllll}
\hline S.No & Solvent system & Samples & Cond. & Dissolved time \\
\hline 1 & Water* & Glycerine & RT & $2 \mathrm{sec}^{*}$ \\
2 & Methanol & Glycerine & RT & $4 \mathrm{sec}$ \\
3 & Ethanol* & Glycerine & RT & 1 sec* \\
4 & Chloroform & Glycerine & RT & immiscible \\
5 & Toluene & Glycerine & RT & Immiscible (bubbles at \\
& & & & bottom) \\
6 & Ethyl acetate & Glycerine & RT & immiscible \\
7 & Glacial acetic acid & Glycerine & RT & 10 sec \\
8 & Formic acid & Glycerine & RT & 2 sec \\
9 & Butyl alcohol & Glycerine & RT & 6 sec \\
10 & Benzene & Glycerine & RT & Immiscible (bubbles at \\
& & & & bottom) \\
11 & Petroleum ether & Glycerine & RT & Immiscible \\
12 & Water* & PEG & RT & 23 sec* \\
13 & Methanol & PEG & RT & 2 min 30 sec \\
14 & Ethanol & PEG & RT & 2 min \\
15 & Chloroform & PEG & RT & 20 sec (white ppt) \\
16 & Toluene & PEG & RT & Immiscible \\
\hline
\end{tabular}

\begin{tabular}{lllll}
\hline 17 & Ethyl acetate & PEG & RT & Immiscible \\
18 & Glacial acetic acid & PEG & RT & $2 \mathrm{~min} 30 \mathrm{sec}$ \\
19 & Formic acid & PEG & RT & $30 \mathrm{sec}$ \\
20 & Butyl alcohol & PEG & RT & Immiscible \\
21 & Benzene & PEG & RT & $50 \mathrm{sec}$ \\
22 & Petroleum ether & PEG & RT & Immiscible \\
23 & - & $10 \%$ PEG & RT & $1 \mathrm{~min}$ \\
24 & - & $25 \%$ PEG & RT & $3 \mathrm{~min}$ \\
25 & - & $50 \%$ PEG & RT & $8 \mathrm{~min}$ \\
26 & - & $100 \%$ PEG & RT & $26 \mathrm{~min}$ \\
27 & - & $10 \%$ PEG & Boiled at $70{ }^{\circ} \mathrm{C}$ & $20 \mathrm{sec}$ \\
28 & - & $25 \%$ PEG & Boiled at $70^{\circ} \mathrm{C}$ & $35 \mathrm{sec}$ \\
29 & - & $50 \%$ PEG & Boiled at $70^{\circ} \mathrm{C}$ & $45 \mathrm{sec}$ \\
30 & - & $100 \%$ PEG & Boiled at $70{ }^{\circ} \mathrm{C}$ & $1 \mathrm{~min} 40 \mathrm{sec}$ \\
\hline Note: ${ }^{*}$ represent quick solubility
\end{tabular}

\subsection{SEM Analysis}

The SEM analysis of OS-SNP, OB-SNP and the films that are synthesized by leaf extracts of Ocimum species labelled OS/SNP/PEG and OB/SNP/PEG have done. The Fig. 8 shows the SEM analysis of the SNP and film, yet the film or the composite were devoid of glycerine since the dry sample is required for SEM characterization, thus glycerine was not added in film for investigation of SEM characters. The shape of OS-SNP is spherical, OB-SNP is like bright contrast coral reef, OS/SNP/PEG composite shape is kind of rosette shape and OB/SNP/PEG is somewhat irregular in shape.

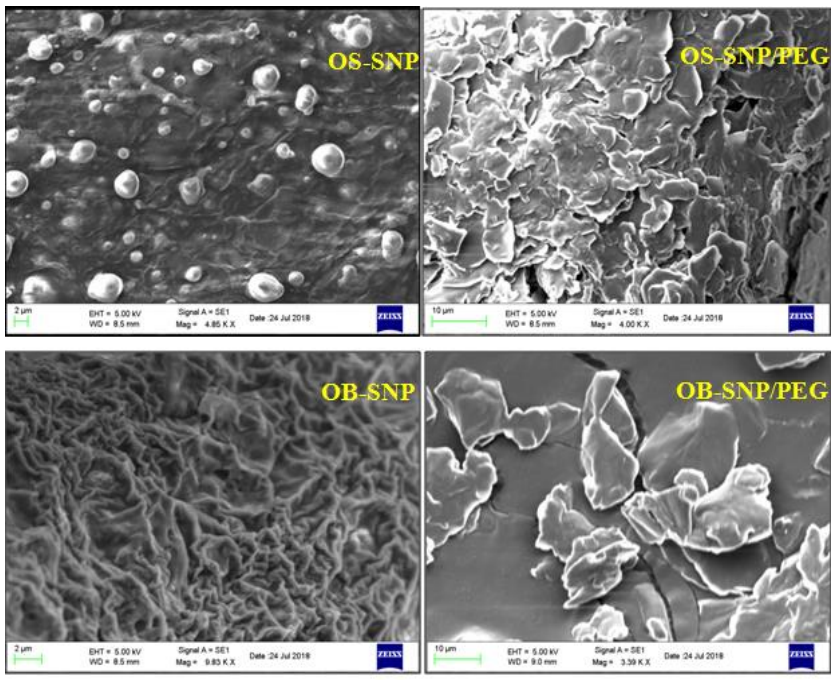

Fig. 8 SEM images of Ocimum sanctum-SNP, Ocimumbasilicum-SNP, Ocimum sanctum-SNP/PEG and Ocimum basilicum-SNP/PEG

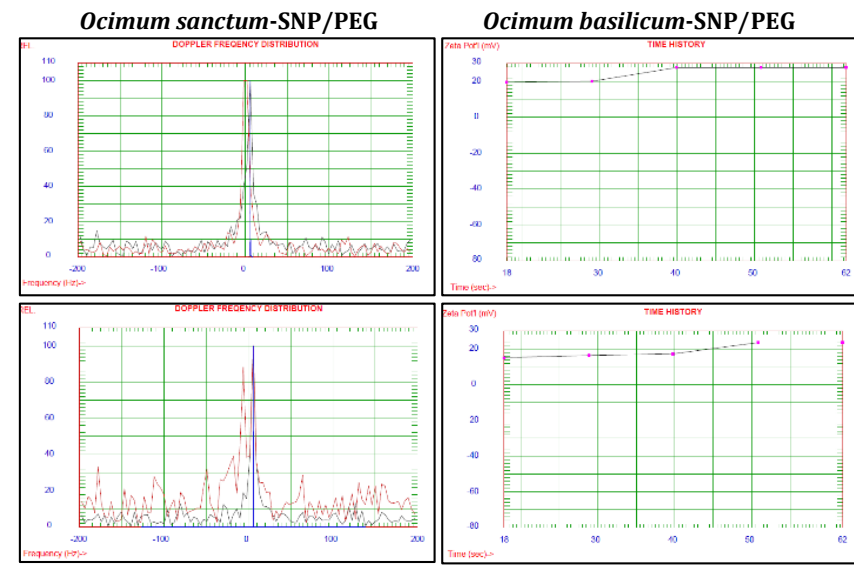

Fig. 9 Zeta potential of silver nanoparticles in Ocimum sanctum-SNP/PEG and Ocimum basilicum-SNP/PEG

\subsection{DLS Size and Zeta Potential Analysis}

The average zeta potential was found to be $27.74 \mathrm{mV}$ and $23.50 \mathrm{mV}$ for with average mobility is 2.07 M.U. and 1.75 M.U for silver nanoparticles integrated in Ocimum sanctum-SNP/PEG and Ocimum basilicum-SNP/PEG film respectively. The doppler frequency distribution to identify zeta potential and time history for $1 \mathrm{~min}$ are represented in Fig. 9. The size and intensities of silver nanoparticles in composite Ocimum sanctum-SNP/PEG and Ocimum basilicum-SNP/PEG is shown in Fig. 10. 


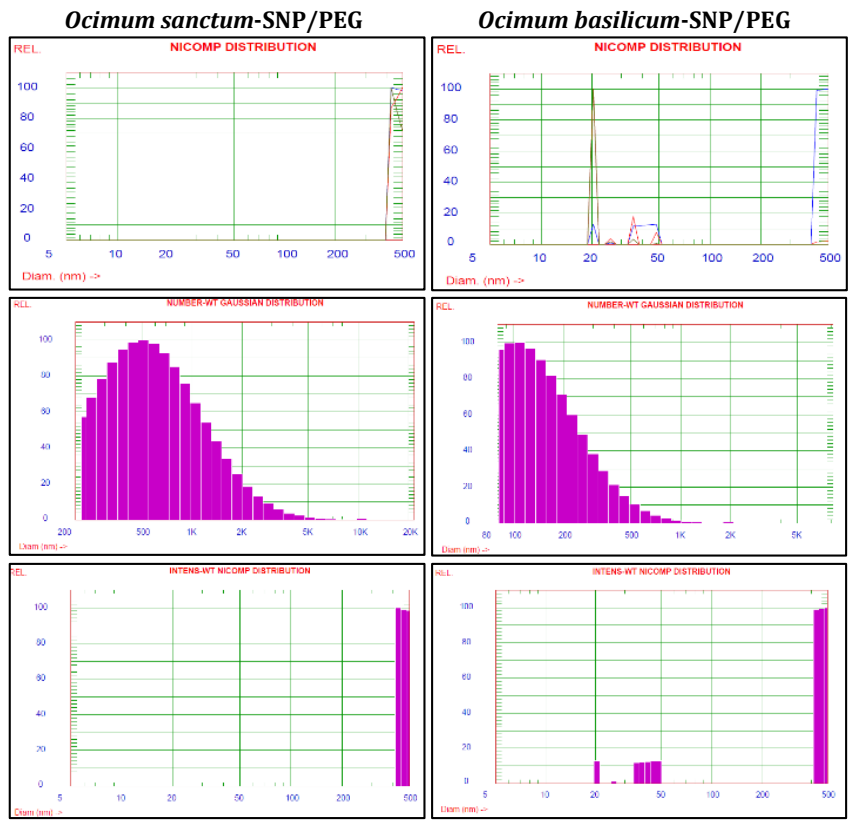

Fig. 10 Dynamic light scattering (DLS) characterization of silver nanoparticles in form of size, distribution and intensities in Ocimum sanctum-SNP/PEG and Ocimum basilicum-SNP/PEG film

In present study, the silver nanoparticles from the leaf extract of Ocimum sanctum (OS) and Ocimum basilicum (OB) have synthesized successfully and exhibited absorption peak at $420 \mathrm{~nm}$ for 0 . basilicum while $410 \mathrm{~nm}$ for 0 . sanctum. Similarly, the research of Malapermal [13] shows the absorption peak at $438 \mathrm{~nm}$ from $O$. basilicum and $439 \mathrm{~nm}$ for $O$. sanctum. The difference in SNP absorption peak may be due to the involvement of different functional group and the method adopted for leaf extract preparation. The films containing nanoparticles such as OSSNP/PEG/G, OB-SNP/PEG/G have been evaluated for presence of silver nanoparticles using UV spectroscopic analysis in range $300 \mathrm{~nm}-800 \mathrm{~nm}$ and a sharp peak around $400-4500 \mathrm{~nm}$ confirms silver nanoparticles incorporated in polymers, besides it was observed that the nanoparticles were stable for 45 days (Fig. 3). The wider range of chemical groups present in aqueous extract of Ocimum sanctum are alkynes (terminal), $1^{\circ}$, $2^{\circ}$ amines, amides, nitriles, alkynes, alkanes and alkyl halides. Similarly, alkynes (terminal), aldehydes, alkynes and alkenes are found in Ocimum basilicum are mainly responsible for reduction of $\mathrm{Ag}^{+}$ions to zero valent $\mathrm{Ag}^{0}$.

The FTIR spectra of the crude aqueous extract and SNPs derived from O. sanctum showed a decrease in stretching frequency from 3333.204 to $3328.169 \mathrm{~cm}^{-1}$ suggesting an alkynes functional group. In the same way, Malapermal [13] suggested the range of $3250-3400 \mathrm{~cm}^{-1}$ for amide region. Furthermore a shift from 1638.683 to $1636.350 \mathrm{~cm}^{-1}$ is assigned to the N$\mathrm{H}$ bend and alkenes, whereas peaks at $1217.445,95.397 \mathrm{~cm}^{-1}$ can be attributed to alkyl halides. The other groups that found are $1^{\circ}, 2^{\circ}$ amines, amides, nitriles, and alkyl halides. In contrast, 0 . basilicum consist of aldehydes, which shift from 2270.803 to $2119.810 \mathrm{~cm}^{-1}$. Overall, the FTIR analysis predicts that SNP have formed using $O$. sanctum and 0 . basilicum extracts confirming the involvement of $-\mathrm{C} \equiv \mathrm{C}-\mathrm{H}$ : $\mathrm{C}-\mathrm{H}$ stretch and $\mathrm{H}-\mathrm{C}=\mathrm{O}$ : $\mathrm{C}-\mathrm{H}$ stretch respectively (Table 2).

The nature of Oscimum sanctum-NP and Oscimum basillicum-NP are colloidal and are capped using respective phyto chemical present in extract of Oscimum species. The reference was set to zero using both plant extract as well as water, they have generated the concentration of Oscimum sanctum-NP, Oscimum basillicum-NP using nanophotometer as 0.900 picomole $/ \mu \mathrm{L}$ and 3.500 picomole $/ \mu \mathrm{L}$ respectively.

The film of composite of $O$. sanctum-NP and $O$. basillicum-NP was formulated which was used to depict the solubility of in water. Beside, individual PEG and glycerine was also used to check the solubility in different solvents (Table 3). The polymer PEG is dissolved in water by two methods: room temperature and boiling at $70{ }^{\circ} \mathrm{C}$ for $20 \mathrm{~min}$. It was observed that the boiling of PEG makes it to dissolve quickly in water when compare with room temperature method. The 10\% PEG dissolved in $1 \mathrm{~min}$ at room temperature whereas; at $70{ }^{\circ} \mathrm{C}$ it was dissolved in $20 \mathrm{sec}$. Also, $100 \%$ PEG in room temperature requires $26 \mathrm{~min}$, however on boiling at 70 ${ }^{\circ} \mathrm{C}$ takes less time of $1 \mathrm{~min} 40 \mathrm{sec}$. The boiling process for film formation was found more efficient than room temperature method. There are various papers on silver nanoparticles synthesis using PEG with combination of other polymer such as glucose [14] however none is there with glycerine.

https://doi.org/10.30799/jnst.161.18040517
The texture and solubility of synthesized films of $O$. basilicum/ $S N P / P E G / G$ and $O$. sanctum $/ S N P / P E G / G$ with different concentration of $P E G$ and $G$ are discussed. The film texture of sample A, B, 1, 2 are observed as to be good, transparent and dries at RT in more time as compare to $\mathrm{C}$, D,E, F, 3, 4, 5 and 6 that shows crystals formation and dried quickly. The $O$. basilicum/SNP/PEG/G (A, B) and $O$. sanctum $/ S N P / P E G / G(1,2)$ dissolved and mixed in $15 \mathrm{~min}$ at $70{ }^{\circ} \mathrm{C}$ whereas, sample $O$. basilicum/ SNP/PEG/G $(\mathrm{C}, \mathrm{D})$ and $O$. sanctum /SNP/PEG/G $(3,4)$ were dissolved and mixed in 30 min at $70{ }^{\circ} \mathrm{C}$. The samples 1,2 and $\mathrm{A}, \mathrm{B}$ forms films effectively, from these sample 2 and B (150\%PEG+150\%G) are finalized. However, samples D and 4 are inefficient to form films. In sample $C$ and 3 crystals formation was observed during film formation. In comparison, D and 4 sample films are not formed properly and large amounts of crystals formed during air drying.

The solubility of polymer and release of silver nanoparticles from composite was studied by applying distilled water over film and evaluating the time and quantity of water requires for dissolving it. The $O$. basilicum $/ S N P / P E G / G$ samples A: $(100 \% \mathrm{PEG}+100 \% \mathrm{G})$, B: $(150 \% \mathrm{PEG}+150 \% \mathrm{G})$ are soluble in $1 \mathrm{~mL}$ and $2 \mathrm{~mL}$ of water that requires about $1 \mathrm{~min} 2 \mathrm{sec}$ and $2 \mathrm{~min} 6 \mathrm{sec}$ to get dissolved respectively. In contrast, the samples E: $(10 \% \mathrm{PEG}+10 \% \mathrm{G}), \mathrm{F}:(50 \% \mathrm{PEG}+50 \% \mathrm{G})$ are soluble in $5 \mathrm{~mL}$ and $10 \mathrm{~mL}$ of water that requires about $1 \mathrm{~min} 30 \mathrm{sec}$ and $2 \mathrm{~min} 10 \mathrm{sec}$ to get dissolved respectively. Similarly the 0 . sanctum $/ S N P / P E G / G$ samples1: $(100 \% \mathrm{PEG}+100 \% \mathrm{G}), 2:(150 \% \mathrm{PEG}+150 \% \mathrm{G})$ are soluble in $2 \mathrm{~mL}$ and $3 \mathrm{~mL}$ of water that requires about $1 \mathrm{~min} 8 \mathrm{sec}$ and $1 \mathrm{~min}$ to get dissolved respectively. However, the sample 5: (10\%PEG+10\%G), 6: $(50 \% \mathrm{PEG}+50 \% \mathrm{G})$ are soluble in $6 \mathrm{~mL}$ and $12 \mathrm{~mL}$ of water that requires about $1 \mathrm{~min} 30 \mathrm{sec}$ and $2 \mathrm{~min} 50 \mathrm{sec}$ to dissolve respectively. The film formed with the PEG and G (100\%:100\% and 150\%:150\%) in 1:1 ratio were dissolved quickly as compare to other concentration combinations. The light microscopic structure of films for sample A, B, 1 and 2 are shown in Fig. 5. It can be observed that in sample 2 and $B$, there is uniform distribution of silver nanoparticles in PEG and glycerine (1:1) film of $150 \%$ concentration and it allows slow liquefy of polymer and efficient release of silver nanoparticles, furthermore the texture and dissolved ability is very good as compare to samples 1 and A. The SEM analysis confirms the spherical shape of OS/SNP and bright contrast coral reef morphology for OB/SNP at $2 \mu \mathrm{m}$ scale similarly, OS/SNP/PEG and OB/SNP/PEG composite show rosette and irregular shape morphology respectively in $10 \mu \mathrm{m}$ scale.

The zeta potential of silver nanoparticles integrated in Ocimum sanctum-SNP/PEG were calculated in range of 5.20 to 6.48 Freq. Shift(Hz) and found to be $24.62(\mathrm{mV})$ to $30.66(\mathrm{mV})$. In same fashion the zeta potential of silver nanoparticles in Ocimum basilicum-SNP/PEG film were -27.61 to 36.72 Freq. Shift(Hz) and found to be -115.99 and $154.27(\mathrm{mV})$. The silver nanoparticles mean diameter $(\mathrm{nm})$ in term of intensity weighting, volume weighting and number weighting in composite Ocimum sanctum-SNP/PEG was found to be 463.2, 465.1 and $459.5 \mathrm{~nm}$. Beside cumulative result based on number-weighted Gaussian distribution confirms the presence of SNP show that the SNP in same composite have $25 \%$ of distribution $<402.8 \mathrm{~nm}, 50 \%$ of distribution $<606.6 \mathrm{~nm}, 75 \%$ of distribution $<972.9 \mathrm{~nm}, 90 \%$ of distribution $<1527.9 \mathrm{~nm}, 99 \%$ of distribution $<3409.4 \mathrm{~nm}$ and $80 \%$ of distribution < $1099.7 \mathrm{~nm}$. However, mean diameter (nm) in term of intensity weighting and volume weighting in composite Ocimum basilicum-SNP/PEG was found to be 43.0 and 465.4 nm. Additionally, the cumulative result based on number-weighted Gaussian distribution confirms the presence of SNP, 25\% of distribution < $122.8 \mathrm{~nm}, 50 \%$ of distribution $<163.9 \mathrm{~nm}, 75 \%$ of distribution $<239.6 \mathrm{~nm}$, $90 \%$ of distribution $<354.2 \mathrm{~nm}, 99 \%$ of distribution $<735.0 \mathrm{~nm}$ and $80 \%$ of distribution $<265.9 \mathrm{~nm}$. Therefore the composite of SNP of average diameters $463.2 \mathrm{~nm}$ in Ocimum sanctum-SNP/PEG and $43.0 \mathrm{~nm}$ in Ocimum basilicum-SNP/PEG could inhibit pathogens. However we could not observed such activity that may be due to some unknown reasons which is still unclear. Pinzaru [15] used PEG-coated SNPs for in vitro and in vivo studies in mice for a toxicological studies.

\section{Conclusion}

In conclusion, this study shows that the aqueous soluble compounds presents in leaf extract of $O$. sanctum and $O$. basilicum are efficient for fabrication of silver nanoparticles, in addition biopolymer composite formulation is possible using PEG and glycerine. The SNP are synthesized in presence of sun light, at alkaline $\mathrm{pH} 8$ and change in solution from light green to dark brown was observed. The characterization done successfully and UV- spectroscopic analysis confirms at $410 \mathrm{~nm}$ to $420 \mathrm{~nm}$ for $O$. sanctum/SNP, O. basilicum/SNP and a sharp peak around 400-4500 nm confirms silver nanoparticles incorporated in polymers composite OSSNP/PEG/G, OB-SNP/PEG/G. The FTIR determines the involvement of alkanes, alkyne, amines, amides, nitriles and alkyl halides in aqueous 
extract of $O$. sanctum and alkynes, aldehydes and alkenes in 0 . basilicum as sole stabilizing agents for silver ions. The optimized film $O$. sanctum $/ S N P / P E G / G$ and $O$. sanctum $/ S N P / P E G / G(150 \% \mathrm{PEG}+150 \% \mathrm{G})$ are best in texture, film forming ability, quickly dissolve in water and slow release of SNP. The SEM characterization confirms the spherical shape and bright contrast coral reef for OS-SNP and OB-SNP respectively; although the SNP incorporated film of $O$. sanctum OS/SNP/PEG has rosette shape while $O$. basilicum based OB/SNP/PEG film is irregular in shape. The average zeta potential was found to be $27.74 \mathrm{mV}$ and $23.50 \mathrm{mV}$ for with average mobility is $2.07 \mathrm{MU}$ and $1.75 \mathrm{MU}$ for silver nanoparticles integrated in Ocimum sanctum-SNP/PEG and Ocimum basilicum-SNP/PEGfilm respectively. The Ocimum basilicum-SNP/PEG have much stable and SNP below $100 \mathrm{~nm}$ ie., $43.0 \mathrm{~nm}$ as compare to Ocimum sanctum-SNP/PEG which have SNP of average diameters $463.2 \mathrm{~nm}$ and could demonstrate study for its antimicrobial potential against E. coli and S. aureous pathogens which could be possible for development of products helpful in medical application.

\section{Acknowledgments}

Our first thanks to Department of Botany for providing research facility and thankful to Prof \& Head Dr. Dr. Tadikamalla Srinivasu, FBS Department of Botany, RTM Nagpur University for permitting to carry out research work. Authors thanks to CICR-CIRCOT, Mumbai, India for DLS and ZETA analysis.

\section{References}

[1] T. Chowdhary, A. Mandal, S.C. Roy, D.D. Sarkar, Diversity of the genus Ocimum (Lamiaceae) through morpho-molecular (RAPD) and (GC-MS) analysis, Genet. Eng. Biotech. 15(1) (2017) 275-286.

[2] S.M.A. Razavi, S. Naji-Tabasi, Rheology and texture of basil seed gum: A new hydrocolloid source, Chapter 16: Advances in Food Rheology and Its Applications, Wood Head Publishing Series Food Science, Technology and Nutrition, Iran, 2017, pp.405-435.
[3] S. Tchatchouang, V.P. Beng, V. Kuete, Antiemetic African medicinal spices and vegetables, Chapter 11: Medicinal spices and vegetables from Africa, Therapeutic potential against metabolic, inflammatory, infectious and systemic diseases, Science Direct, Elsevier, 2017, pp.299-313.

[4] Kumar, S. Kumari, Pharmacological properties of tulsi: A review, Int. J. Ayur. Herbal Medi. 5(4) (2015) 1941-1948.

[5] S. Bhateja, G. Arora, Therapeutic benefits of basil (tulsi) in general and oral medicine: A review, Int. J. Ayur. Pharma. 3(6) (2012) 761-764.

[6] J.P. Dzoyem, L.J. Mcgaw, V. Kuete,U. Bakowsky, Anti-inflammatory and Antinociceptive activities of African medicinal spices and vegetables, Chapter 9: Medicinal spices and vegetables from Africa, Therapeutic potential against metabolic, inflammatory, infectious and systemic diseases, Academic press, COUNTRY, 2017, pp.239-270.

[7] B.D. Lade, A.S. Patil, Silver nano fabrication using leaf disc of Passiflora foetida Linn., Appl. Nanosci. 7(5) (2017) 181-190.

[8] Webmd, Drugs \& medications, polyethylene glycol 335017 gram/dose ora powder, generic name(s): polyethylene glycol 2017. https://www.webmd.com/drugs/2/drug-17118/polyethylene-glycol-3350oral/details (Accessed on: 12.07.2018)

[9] Sigma Aldrich, Polyethylene Glycol (PEG) Selection Guide, 2017. https://www.sigmaaldrich.com/technical-documents/articles/materialscience/polyethylene-glycol-selection-guide.html (Accessed on: 22.07.2018)

[10] H.A. Yamani, E.C. Pang, N. Mantri, M.A. Deighton, Antimicrobial activity of tulsi (Ocimum tenuiflorum) Essential oil and their major constituents against three species of bacteria, Front Microbiol. 7(681) (2016) 1-10.

[11] R.K. Joshi, Chemical composition and antimicrobial activity of the essential oil of Ocimum basilicum L. (sweet basil) from Western Ghats of North West Karnataka, India, Anc. Sci. Life, 33(3) (2014) 151-156.

[12] H. Gebrehiwot, R.K. Bachheti, A. Dekebo, Chemical composition and antimicrobial activities of leaves of sweet basil (Ocimum basilicum L.) herb, Int. J. Basic Clin. Pharmacol. 4(5) (2015) 869-875.

[13] V. Malapermal, I. Botha, S.B.N. Krishna, J.N. Mbatha, Enhancing antidiabitic and antimicrobial performance of Ocimum basilicum and Ocimum sanctum (L.) using silver nanoparticles, Saudi J. Biol. Sci. 24 (2017) 1294-1305.

[14] K. Shameli, M.B. Ahmad, S.D. Jazayeri, S. Sedaghat, P. Shabanzadeh, H Jahangirian, et al., Synthesis and Characterization of polyethylene glycol mediated silver nanoparticles by the green method, Int. J. Mol. Sci. 13(6) (2012) 6639-6650.

[15] I. Pinzarua, D. Coricovaca, C. Deheleana, E.A. Moacăa, M. Mioca, et al., Stable PEG-coated silver nanoparticles - A comprehensive toxicological profile, Food Chem. Toxicol. 111 (2017) 546-556. 